\title{
ALGUNAS CONSIDERACIONES ACERCA DEL NUEVO PAPEL DE LA ENTIDAD GESTORA ANTE EL POSIBLE USO FRAUDULENTO DE LA CONTRATACION TEMPORAL ${ }^{1}$
}

\author{
Sol Ruiz de la Cuesta Fernández \\ Profesora Asociada del Departamento \\ de Derecho del Trabajo y de la Seguridad Social \\ Universidad de Alicante
}

\begin{abstract}
Sumario: 1. Breve recordatorio: denegación de prestaciones por inexistencia de situación legal de desempleo. 2. Refuerzo normativo con base en la jurisprudencia y nuevo papel de las Entidades Gestoras ante la contratación temporal fraudulenta. 3. El nuevo art. 145 bis LPL: breves apuntes para una aproximación. 4. Valoración final.
\end{abstract}

\section{Breve recordatorio: denegación de prestaciones por inexistencia de situación legal de desempleo}

El artículo $208 \mathrm{LGSS}^{2}$, en su apartado 1, número 1, letra f), considera que se encontrará en situación legal de desempleo el trabajador vinculado temporalmente a su empresario cuando se produzca la expiración del tiempo convenido o tenga lugar la realización de la obra o servicio objeto del contrato, «siempre que dichas causas no hayan actuado por denuncia del trabajador». Por su parte, el número 2 del apartado 2 del mismo precepto no consideraba en situación legal de desempleo a quien, habiendo sido despedido, no reclamase en tiempo y forma contra la decisión empresarial ${ }^{3}$. Pues bien, a partir de una censurable interpretación de este último precepto, las Entidades Gestoras de la Seguridad Social venían denegando las solicitudes de prestaciones por desempleo en los casos en los que, siendo el solicitante un trabajador que había estado vinculado temporalmente a la empresa, existieran indicios de tratarse en realidad de una relación laboral indefinida, por haberse actuado de forma fraudulenta en el uso de la contratación temporal. Ese

\footnotetext{
1 Adaptación de la Comunicación presentada a las I Jornadas Universitarias Valencianas de Derecho del Trabajo y de la Seguridad Social, 7 y 8 de marzo, Alicante, 2003.

2 Real Decreto Legislativo 1/1994, de 20 junio, por el que se aprueba el Texto Refundido de la Ley General de la Seguridad Social.

${ }^{3}$ Salvo en el caso de despidos basados en causas objetivas.
} 
uso abusivo, entendía el Ente Gestor, calificaba el contrato de indefinido, de tal modo que el aquietamiento del trabajador frente a la decisión extintiva empresarial se venía interpretando, según los supuestos, bien como extinción consentida, bien como despido frente al que el trabajador no reaccionó ${ }^{4}$. En ambos casos la consecuencia era el rechazo de la solicitud por inexistencia de situación legal de desempleo.

El Tribunal Supremo, sin embargo, se pronunció repetidamente al respecto ${ }^{5}$, señalando que cuando el vínculo mantiene una apariencia de temporalidad y se produce la extinción por las causas previstas en el contrato, no cabe imponer al trabajador la exigencia inexcusable de que demande por despido para que nazca el derecho a la prestación de desempleo, pues eso supondría atribuirle una carga que no viene establecida en la Ley, la que sólo requiere que se acredite el hecho cierto de la extinción del contrato temporal por la voluntad del empresario con base en las causas válidamente establecidas en el mismo.

\section{Refuerzo normativo con base en la jurisprudencia y nuevo papel de la Entidad Gestora ante la contratación temporal fraudulenta}

Cerrando el paso definitivamente a aquella interpretación que venían realizando las Entidades Gestoras de la Seguridad Social, el Real Decreto-Ley 5/2002, de 24 de mayo, de Medidas Urgentes para la Reforma del Sistema de Protección por Desempleo y Mejora de la Ocupabili$\operatorname{dad}^{6}$ añadió un nuevo apartado 4 al artículo 208 LGSS, relativo a la solicitud y nacimiento del derecho a la prestación, en el que se hace constar que «en el supuesto de despido o extinción de la relación laboral, la decisión del empresario de extinguir dicha relación se entenderá, por sí misma y sin necesidad de impugnación, como causa de situación legal de desempleo». A partir de esta expresísima indicación legal se deja indubitado constancia de que la extinción de un contrato temporal, al margen de su eventual fraudulencia, no requiere en modo alguno de

${ }^{4}$ Cfr., Albiol Montesinos, I. y Blasco Pellicer, A., Desempleo y despido en la reforma laboral del Real Decreto-Ley 5/2002, Tirant Lo Blanch, Colección Laboral, n. ${ }^{\circ}$ 136, Valencia, 2002, pp. 85 y 86.

5 STS de 2 de abril de 1984. RJ 2021, dictada en recurso de interés de la ley; STS de 7 de mayo de 1994, RJ 4006; STS de 20 de diciembre de 1995, u.d., AR, 9487; STS 6 marzo de 2001 ud, AR 2835, entre otras. Sorprende la reciente STS de 29 de enero de 2002, RJ 5976, que se aparta de esta línea jurisprudencial y deniega el subsidio de desempleo a una trabajadora eventual por considerar que la verdadera naturaleza del vínculo contractual era del contrato fijo discontinuo.

${ }^{6}$ BOE 25 de mayo. 
impugnación por parte del trabajador, conclusión a la que no obstante, como se señaló, debía haberse llegado igualmente a partir de la anterior normativa ${ }^{7}$. En definitiva, y por si alguna duda pudiera asaltar todavía a los Entes Gestores, resulta ya de todo punto imposible aquella interpretación conducente a la denegación de una solicitud de prestaciones que reúna los requisitos previstos por la LGSS, por mucha sospecha de fraudulencia que la contratación temporal extinguida pudiera infundir. Así las cosas, extinto el contrato temporal que vinculaba al trabajador con el empresario y solicitada por aquél la prestación en tiempo y forma, en cuanto reúna todos los requisitos habrá de serle concedida.

Paralelamente a esta nueva regulación, el RDL 5/2002 articuló un nuevo cauce de actuación de la Entidad Gestora para esos específicos supuestos en los que la contratación temporal pudiera revelarse como fraudulenta. A través de la DA Tercera se estableció un sorprendente proceso mediante el cual, y ante la probable existencia de fraude a la ley en materia de contratación temporal, la Entidad Gestora podría comunicarlo a la autoridad judicial, demandando la declaración de la relación laboral como indefinida y la readmisión del trabajador, al tiempo que se establecía el reconocimiento provisional de la prestación y, en caso de sentencia estimatoria firme, la aplicación de lo previsto en la letra b) del apartado 5 del artículo 209 LGSS $^{8}$. Los objetivos perseguidos a través de esta novedosa disposición eran, desde luego, plausibles: se trataba de arbitrar un mecanismo que posibilitara al Ente Gestor la recuperación de prestaciones indebidas (las abonadas como consecuencia de la extinción de ese último contrato temporal y aquellas otras que se hubieran podido percibir durante la secuencia contractual declarada

7 «En realidad, no parece que fuera preciso crear una nueva situación legal de desempleo porque quien cesa por expiración del término en un contrato de trabajo temporal está ya en la situación prevista en el artículo 208.1.1.f) LGSS. Pero se trata sólo de una aclaración», Desdentado Bonete, A. y De la Puebla Pinilla, A., en AAVV, Coord. García-Perrote, I., La Ley 45/2002 de reforma de la protección por desempleo (La «reforma» de la reforma del despido, de los salarios de tramitación y del desempleo), Lex Nova, Valladolid, 2003, p. 40.

8 También introducido por el mismo RDL 5/2002: «Cuando, como consecuencia de la reclamación o el recurso se produzca la readmisión del trabajador, mediante conciliación o sentencia firme (...) las cantidades percibidas por éste en concepto de prestaciones por desempleo se considerarán indebidas por causa no imputable al trabajador. En tal caso, la Entidad Gestora cesará en el abono de las prestaciones por desempleo y reclamará las cotizaciones de Seguridad Social efectuadas. El empresario deberá ingresar a la Entidad Gestora las cantidades percibidas por el trabajador, deduciéndolas de los salarios dejados de percibir que hubieran correspondido según lo establecido en el apartado 57.1 de la Ley del Estatuto de los Trabajadores, con el límite de la suma de tales salarios». 
fraudulenta, así como las correspondientes cotizaciones), asegurando de este modo que la pasividad del trabajador ante un uso abusivo de la contratación temporal no repercutiría negativamente en los activos patrimoniales de la Seguridad Social. Puesto que no es posible descargar sobre el trabajador la responsabilidad de la falta de impugnación, ese papel activo, antes exigido por el Ente Gestor al solicitante de la prestación, se traslada directamente a aquél, con cuya actuación se consigue no sólo el objetivo recaudatorio inmediatamente perseguido por la norma (con el que se intenta compensar, probablemente, la merma en el ahorro que la denegación de prestaciones suponía), sino también, si bien de manera mediata o instrumental, el no menos importante de restablecer el orden jurídico que pretendió eludirse a través del fraude de ley, con las consecuencias que de ello se derivaban sobre la esfera contractual del trabajador.

Sin embargo, siendo, como se dijo, loable la intención del ejecutivo, la DA Tercera del RDL 5/2002 nació asentada sobre una serie de desajustes y problemas de hondísimo calado, de los que la doctrina no tardó en hacerse eco y relacionados en su mayoría con la estructura procesal de la actuación prevista. La primera de las observaciones que podían hacerse quedaba referida al instrumento normativo empleado para introducir esta nueva acción, una norma de naturaleza sustantiva que en modo alguno modificaba la Ley de Procedimiento Laboral pero que a ella reenviaba implícitamente, lo cual es, desde el punto de vista de la técnica legislativa, todo un dislate ${ }^{9}$. El reenvío a la norma procesal era necesario, no obstante, si se querían colmar las múltiples lagunas que ese nuevo proceso presentaba. En primer lugar, ¿cuál debía ser el cauce procesal adecuado?, porque, pese a una superficial apariencia, no parecía ser en puridad materia de Segundad Social ${ }^{10}$.

9 Cfr., Alemán Cano, J., Los procesos de oficio, Colección trabajo y Seguridad Social, n. ${ }^{\circ}$ 13, Comares, Granada, 2003, pp. 131-132. En otro orden de ideas, VALDÉs DAL-RE, F., «Reforma de la protección por desempleo, concertación social y legislación de urgencia (I)», en Relaciones Laborales, n. ${ }^{\circ} 15-16,2002$, p. 13, señala que la DA Tercera del RD-L 5/2002, no innova el ordenamiento jurídico, precisamente por la ausencia de modificación en la norma adjetiva, «no modifica, por decirlo en términos de la SSTC 29/1986, de 31 de mayo, de manera instantánea una situación jurídica existente, por lo que de ella no puede predicarse en absoluto la justificación de extraordinaria y urgente necesidad. La respuesta normativa no puede calificarse de adecuada a la necesidad perseguida».

10 Martínez GiRÓN, J. «Reiteración de la contratación temporal, fomento de la contratación indefinida y fomento de la movilidad geográfica», en $A L, \mathrm{n} .^{\circ} 33$, Número Extraordinario: RDLEY 5/2002: Análisis Técnico-Jurídico, 2002, p. 690, señala que lo ventilado en ese pleito será materia laboral estricta. 
La respuesta prácticamente unánime de la doctrina aterrizó en el terreno de los procesos de oficio (artículos 146-150 LPL) a partir del recurso a la analogía ${ }^{11}$, si bien, claro estaba, «Entidad Gestora» no es «Autoridad Laboral»; algún autor apuntó, sin embargo, que la vía procesal adecuada era la del laboral ordinario ${ }^{12}$. Se pusieron de manifiesto, además, dificultades tales como el carácter y acumulación de las acciones planteadas, el dies a quo, el plazo de actuación o las situaciones litisconsorciales, entre otros ${ }^{13}$. Pero también existían problemas residenciados en la vertiente sustantiva de la disposición, como lo era la incertidumbre doctrinal acerca de si se estaba resucitando la figura del despido nulo radical por fraude de ley ${ }^{14} \mathrm{y}$, en caso de que así fuera, su acotamiento a los supuestos exclusivos de la DA Tercera $^{15}$. En definitiva, eran tantas las lagunas y tan escasa la virtualidad práctica de la solución contemplada que no faltó quien apuntó que «no debería sorprender que durante el trámite parlamentario la referida disposición sufra alguna modificación que la acerque más al establecimiento de algun método a través del cual, a sus propios efectos y sin proyección sobre la esfera contractual del trabajador afectado, se establezca la posibilidad de que la calificación de la verdadera naturaleza indefinida del contrato tenga efectos únicamente en materia de responsabilidad (empresarial) en materia de prestaciones y no en la readmisión del trabajador.» ${ }^{16}$

11 Albiol Montesinos, I. y Blasco Pellicer, A., op. cit., p. 88, si bien con ciertas dudas al preguntarse, desde el mismo título, si nos encontramos o no ante un nuevo proceso de oficio; Alemán CAno, op. cit., pp. 179 y ss.; García-Perrote Escartín, I. y Mercader UguiNA, J. «Reformas en materia laboral del Real Decreto-Ley 5/2002», en AAVV, Comentarios de urgencia a la reforma del sistema de protección por desempleo (Nuevo régimen jurídico del despido, de los salarios de tramitación y del desempleo), Tecnos, 2002, p. 105.

12 MARTínez GiRón, J., op. cit., p. 691, para quien ello explica que el RDL 5/2002, no haya tenido necesidad alguna de enmendar la LPL; SEMPERE NAVARRo, A., «La reforma del despido y el desempleo mediante Real Decreto-Ley 5/2002, de 24 de mayo», en Actualidad Jurídica Aranzadi, n. ${ }^{\circ}$ 536, 2002, p. 7, npp 63.

13 García-Perrote Escartín, I. y Mercader Uguina, op. cit., p. 106.

14 Sin dudas al respecto, MARTínez GiRón, op. cit., p. 692, para quien nos encontrábamos, llanamente, ante la figura del despido objetivo nulo por defecto de forma.

15 Albiol Montesinos, I. y Blasco Pellicer, op. cit., p. 89.

16 García-Perrote Escartín, I. y Mercader Uguina, op. cit., p. 106. Para Ríos SalMERón, B., En AAW, Coord. A. V. Sempere Navarro, Empleo, Despido y Desempleo tras las Reformas de 2002 (Análisis de la Ley 45/2002, de 12 de diciembre), Aranzadi, Navarra, 2003, pp. 108-109, «...el conferimiento de tan genérica legitimación extraordinaria a un tercero, aunque sea un Ente Gestor, implicaba una exagerada intromisión en la privacidad jurídica de un sujeto, que es el trabajador, por más que se piense en la desigualdad material que normalmente sufre.» 


\section{El nuevo artículo 145 bis LPL: breves apuntes para una aproximación}

Y así fue, efectivamente. La Ley 45/2002, de 12 de diciembre, de Medidas Urgentes para la Reforma del Sistema de Protección por Desempleo y Mejora de la Ocupabilidad ${ }^{17}$, manteniendo las modificaciones introducidas por su antecesor en cuanto a la consideración de la situación legal de desempleo ${ }^{18}$, da un giro radical a la actuación de la Entidad Gestora. Como primer acierto de esta nueva regulación se encuentra el de procederse a ella a través de una modificación de la Ley de Procedimiento Laboral con la que se añade un nuevo artículo, el 145 bis (Capítulo VI del Título II, Libro II, De la Seguridad Social) que acoge un novedoso proceso específicamente creado para estos casos. Se colman así las lagunas creadas por la DA Tercera del RD-L 5/2002, de manera que ya no es necesario el recurso a la analogía para decidir cuál es el cauce procesal adecuado, al tiempo que se despejan otra serie de dudas. Se estructura, en definitiva, un proceso acotado y, en este sentido, es de agradecer la infinitamente mayor claridad y precisión del legislador frente a la nebulosa del ejecutivo a través de la DA Tercera. Sin embargo, el nuevo proceso del artículo 145 bis LPL se presenta como un raro híbrido, ubicado en el capítulo relativo a los procesos de Seguridad Social (con los que, como se verá, tiene escasas similitudes) pero asentado sobre pilares propios de los procesos de oficio ${ }^{19}$, además de abrir nuevos interrogantes.

17 BOE 13 de diciembre.

18 E introduciendo un nuevo apartado 4 al artículo 208 LGSS, en el que específicamente se prevé que «En el supuesto previsto en el artículo 145 bis LPL y sin perjuicio de lo señalado en el mismo, los trabajadores se entenderán en la situación legal de desempleo establecida en el párrafo f) del apartado 1 de este artículo por finalización del último contrato temporal y la Entidad Gestora les reconocerá las prestaciones por desempleo si reúnen el resto de los requisitos exigidos».

19 Considerando que «...es más bien el ejercicio de una peculiar acción revisora de anteriores actos administrativos, aunque la letra del precepto aparente lo contrario, cuando dice que la posibilidad establecida por la norma no conllevará la revisión de las resoluciones que hubieran reconocido el derecho a las prestaciones de desempleo. Esto no impide, se insiste, que estemos ante una revisión, bien que muy peculiar», Ríos SALMERón, B., en AAVV, Coord. A. V. Sempere Navarro, Empleo, Despido y Desempleo..., op. cit., p. 109. En similar sentido, Desdentado Bonete, A. y De la Puebla Pinilla, A., en AAVV, Coord. I. García-Perrote, La Ley 45.7/2002, de reforma de la protección..., op. cit., p. 41. Para AlEMÁn CANO, J., Los Procesos de Oficio, op., cit., p. 129, se trata, pese a su ubicación, de un verdadero proceso de oficio»... pese a todo y contra natura, si se toma en consideración la filosofía irradiada por el legislador de la ley procesal laboral y asumida en este nuevo proceso (mimetismo incluido, con el «procedimiento de oficio», y por el tenor del número tercero, apartado a, del art. 145 bis)». Asignándole naturaleza de proceso de Seguridad Social, cfr., Albiol MonTESINOS, I., en AAAVV, Derecho Procesal Laboral, Tirant Lo Blanch, Valencia, 2003, pp. 320-321. 
Por otro lado, y a diferencia de lo que sucedía a partir de la DA Tercera del RDL 5/2002, en el proceso previsto por el artículo 145 bis LPL, se huye de proyección alguna sobre la esfera contractual del trabajador, pues la Entidad Gestora ya no demandará la declaración de la relación laboral como indefinida y la readmisión del trabajador, sino únicamente la condena del empresario al reintegro de prestaciones y cotizaciones, cuando quede probado que existió fraude en la utilización de la contratación temporal. El afán recaudatorio del Ente Gestor no alcanza ahora a esa última prestación solicitada por el trabajador, que será abonada por la demandante sin repetirla de la empresa, sino que queda limitado a prestaciones por desempleo percibidas por el trabajador con anterioridad a esa última extinción contractual (durante los cuatro años anteriores, exactamente) a partir de correlativas extinciones de contratos temporales celebrados con ese mismo empresario. Es por ello que ya no se utiliza el mismo presupuesto de partida para poner en marcha la actuación de la Entidad Gestora: si con la regulación contenida en la DA Tercera del RDL 5/2002, se posibilitaba la reacción del Ente Gestor por la mera contratación temporal con visos de fraudulencia, de cara a recuperar la última prestación por desempleo abonada provisionalmente al trabajador (además de aquellas anteriores que pudieran también ser recobradas), con el nuevo art. 145 bis LPL se introduce expresamente la necesidad de que el trabajador haya percibido prestaciones «por finalización de varios contratos temporales», pues son éstas, y no la última, las que pretenden recuperarse. Desde este punto de vista, debe atenderse a otra importante diferencia entre la actual y la anterior norma: pese a la falta de mención expresa, la doctrina entendió en su momento que la demanda de la Entidad Gestora prevista por la DA Tercera RDL 5/ 2002 no se limitaría únicamente a los supuestos de contratación temporal en cadena, sino que abarcaría también aquellos otros en los que tuvo lugar un único contrato temporal de carácter fraudulento $^{20}$. Esta razonable interpretación decae totalmente a los efectos de la nueva normativa, pues la existencia de un único contrato temporal posiblemente realizado en fraude de ley ya no pondrá en marcha el proceso del artículo 145 bis LPL ${ }^{21}$. Si lo que se pretende recuperar con el nuevo proceso son las prestaciones anteriormente cobradas, y no la última, la existencia de un solo contrato, por muy evidente que pueda resultar su

${ }^{20}$ Martínez Girón, op. cit., p. 693; Albiol Montesinos y Blasco Pellicer, op. cit., pp. 87 y 88 .

21 Así lo observan también García-Perrote Escartín, I. y Mercader Uguina, J.R., en AAVV, Coord. I. García-Perrote Escartín, La Ley 45/2002 de reforma de la protección..., op. cit., p. 131. 
fraudulencia, deviene en no relevante de cara a los objetivos recaudatorios del Ente Gestor.

Por lo demás, se dice que la actuación de la Entidad Gestora no conllevará la revisión de las resoluciones en que se reconocieron dichas prestaciones, considerádose debidas al trabajador ${ }^{22}$, y no deja de sorprender, sin embargo, este artificio con el que se intenta alcanzar el objetivo recaudatorio sin efectos contractuales. Nos encontraremos en estos casos con unas mismas prestaciones que de cara al trabajador tendrán la consideración de debidas, en tanto se calificarán de indebidas, frente al empresario. Y desde luego es la única vía posible para recuperar prestaciones sin incidir directamente en la relación jurídico-laboral, pero desde esta perspectiva, precisamente, no se entiende muy bien porqué la calificación de indebida y la correspondiente repetición del empresario no alcanza también a la última de las prestaciones por desempleo disfrutada por el trabajador. Cierto es que su situación jurídico laboral se ve ahora inalterada, pero la ficción a la que nos referíamos podría perfectamente abrazar también a esa última prestación ${ }^{23}$.

Por lo que se refiere al carácter fraudulento de la contratación temporal, la nueva norma no despeja determinadas incógnitas que ya existían con su antecesora, relativas a los criterios de calificación del fraude de ley. Respecto de la DA Tercera ya se alertó de que la secuencia contractual considerada como posiblemente fraudulenta podría haber sufrido interrupciones superiores a los veinte días entre contrato y contrato ${ }^{24}$, lo que

22 Art. 145 bis 1, párrafo cuarto, LPL.

23 Para Martinez Moya, J. y Buendía Jiménez, A., en AAVV, Coord. A. V. Sempere Navarro, Empleo, Despido y Desempleo tras las Reformas de 2002 (Análisis de la Ley 45/2002, de 12 de diciembre), Aranzadi, Navarra, 2003, p. 158, se trata, sin embargo, de una «... previsión lógica, pues en su nacimiento aparece desconectada de la existencia o no de fraude en la contratación, en sí misma resulta lícita en su causación». Por su parte, Desdentado Bonete, A. y De la Puebla Pinilla, A., en AAVV, Coord. I. García-Perrote Escarpín, La Ley 45/2002 de reforma de la protección..., op. cit., p. 41, entienden que «... la posible improcedencia del cese como consecuencia de la contratación fraudulenta no afecta a la última prestación solicitada, a pesar de que presumiblemente estamos ante el mismo supuesto que ha determinado los ceses anteriores». BLANco Martín, J.M., en AAVV, Dtores. P. Gete Castrillo y F. Valdés Dal-Ré, Nuevo régimen jurídico del Despido y del Desempleo (Análisis crítico de la Ley 45/2002), Cinca, Madrid, 2003, p. 117, manifiesta que «... nos sorprende el hecho de que la devolución no alcance el periodo de prestación por finalización del último contrato temporal, cuando en la mayoría de los casos será este último el que determine lo fraudulento de la cadena total de los mismos».

${ }^{24}$ Cuando así es, sólo procede el examen del último de los contratos celebrados, y no el control de legalidad de toda la cadena contractual, según reiterada doctrina jurisprudencial (SSTS de 29 de mayo de 1997, u.d, Ar. 4473; 6 de julio de 1998, u.d., Ar. 7010; 25 de marzo de 1999, u.d., Ar. 3516; 10 diciembre de 1999, u.d., Ar. 9731). 
dejaba abierta la posibilidad de entender que se estaba arbitrando una especial forma de calificación del fraude, distinta de la prevista con carácter general para los supuestos en los que es el propio trabajador quien ejercita la acción e interpone la pretensión ${ }^{25}$. Como se dijo, esta duda se mantiene con el art. 145 bis LPL. Las combinaciones son muy diversas, pues tan probable será que esos veinte días se hayan rebasado con creces como que no se hayan llegado a consumir, intercalándose incluso enlaces entre uno y otro contrato de duración inferior a los veinte días con otros de duración superior. Cuando los veinte días no se hayan superado la calificación del fraude se apoyará necesariamente en los criterios tradicionalmente suministrados por la Jurisprudencia, pero en los demás supuestos no queda claro cuál deba ser la respuesta. Si entendemos que no se pretende una alteración de los criterios jurisprudenciales, la respuesta restringe sobremanera la actuación de la Entidad Gestora, que sólo accionará cuando la secuencia contractual no presente interrupciones de más de 20 días, de tal modo que el objetivo recaudatorio se ve así altamente mermado. Sin embargo, no debe olvidarse que los tradicionales criterios de calificación del fraude de ley han sido construidos en atención a aquellos plazos de caducidad a los que necesariamente se somete el trabajador a la hora de accionar por despido ${ }^{26}$, de tal manera que podría resultar razonable entender que cuando quien interpone la demanda es el Ente Gestor no tendría por qué verse limitado por ellos.

En cualquier caso, constatado el cobro de prestaciones por la Entidad Gestora e insertos en una secuencia contractual temporal de apariencia fraudulenta, ésta dirigirá comunicación-demanda a la autoridad judicial solicitando la condena del empresario en los términos expresados, siempre que quede probada la fraudulencia de la contratación. El plazo de que dispone el Ente Gestor para dirigir la comunicación («que tendrá la consideración de demanda», dice la norma) al órgano judicial, sin necesidad de conciliación previa ${ }^{27}$, es el de los tres meses siguientes a la fecha en que se hubiera formulado la última solicitud de prestaciones en tiempo y forma ${ }^{28}$. En cuanto a los requisitos de la comunicación-

25 Albiol Montesinos, I. y Blasco Pellicer, op. cit., pp. 89 y 90.

26 Art. 59.3. ET (Texto Refundido aprobado por RD Legislativo 1/1995, de 24 de marzo).

27 Tanto por incluirse dentro de los procesos de seguridad social como por los rasgos propios de los procesos de oficio; en este sentido, GoRELLi HERnÁNDEZ, en AAVV, El nuevo régimen jurídico del despido y del desempleo (Análisis de la Ley 45/2002), Ediciones Laborum, Colección Derecho Laboral (Temas puntuales), Murcia. 2002, p. 72.

28 Art.145 bis 1, párrafo tercero, LPL. El plazo parece ser de prescripción, a falta de previsión en otro sentido. Para Desdentado Bonete, A. y De la Puebla Pinilla, A., en AAVV, Coord. I. García-Perrote Escarpín, La Ley 45/2002 de reforma de la protección, op. cit., p. 41, el plazo es de caducidad. 
demanda, se exigen los propios de los procesos ordinarios ${ }^{29}$, disponiendo la demandante de un plazo de diez días para la subsanación de defectos $\mathrm{u}$ omisiones $\mathrm{s}^{30} \mathrm{y}$ debiendo acompañar a ella copia del expediente o expedientes administrativos en que se fundamente ${ }^{31}$, característica esta última propia de los procesos de Seguridad Social ${ }^{32}$. Admitida la demanda a trámite el proceso continuará por los cauces propios del ordinario, con determinadas especialidades. En primer lugar, se indica que empresario y trabajador serán parte en el proceso, no pudiendo ninguno de ellos solicitar la suspensión ni el trabajador desistir; en caso de que no asistieran, el proceso se seguiría de oficio ${ }^{33}$. Se trata, claramente, de la importación de un rasgo propio de los procesos de oficio regulados por los artículos 146 a 150 LPL. Que el empresario debe ser parte en el proceso resulta lógico, pues contra él se dirigirá la demanda. La posición como parte del trabajador no resulta, en principio, tan razonable ${ }^{34}$.

Tomando como punto de partida el dato de que la llamada del trabajador al proceso se asienta sobre postulados propios de los procesos de oficio, resulta sin embargo que en éstos la Autoridad Laboral tan sólo impulsa el procedimiento, sin constituirse como parte del mismo, pues no es la titular del interés legítimo debatido ni tampoco de la relación jurídica material sobre la que se litiga ${ }^{35}$, de tal forma que el trabajador, verdadero titular de los mismos, es considerado parte en estos procesos. Sin embargo, en el proceso que nos ocupa la Entidad Gestora no es una mera impulsora del mismo, sino parte legítima; de hecho, la estimación o desestimación de su pretensión de condena afecta únicamente a la

\footnotetext{
29 Arts. 80 y ss. LPL.

30 Art. 145 bis 2 LPL.

31 Art. 145 bis 1, párrafo segundo. LPL.

32 Arts. 139 a 145 LPL.

${ }^{33}$ Letra a) del n. ${ }^{\circ}$ 3, art. 145 bis LPL.
}

34 Para Ríos Salmerón, B., en AAVV, Coord. A. V. Sempere Navarro, Empleo, Despido y Desempleo..., op. cit., p. 111, el trabajador es un mero co-litigante de la Administración. Martínez Moya, J. y Buendía Jiménez, A., en AAVV, Coord. A. V. Sempere Navarro, Empleo, Despido y Desempleo... op. cit., pp. 158 y 159, señalan que la referencia normativa al desistimiento del trabajador podría conducir a pensar que «... Ia posición del trabajador es la de demandante o litisconsorte activo necesario, pero con ciertas facultades disminuidas respecto de la parte demandante principal». Para Desdentado Bonete, A. y De la Puebla Pinilla, A., en AAVV, Coord. I. García-Perrote Escarpín, La Ley 45/2002 de reforma de la protección..., op. cit., p. 42, el trabajador sólo puede considerarse un interviniente, sin una posición de interés clara para todos los supuestos, pues su derecho a las prestaciones no queda afectado por la sentencia.

35 En este sentido, cfr. Montero Aroca, Iglesias Cabero, Marín Correa y SampeDRo Del Corral, Comentarios a la Ley de Procedimiento Laboral (Tomo I), Civitas, Madrid, 1993, pp. 862-866. 
relación deudor-acreedor que se establece entre ella y el empresario, sin que la sentencia (eliminada ya aquella posibilidad contemplada por la DA Tercera del RDL 5/2002) produzca efecto alguno en la esfera contractual del trabajador. Cierto es que para que la pretensión de la Entidad Gestora sea estimada será necesaria una previa prueba del fraude de ley, momento en el que el debate girará desde luego en torno a una relación de la que el trabajador sí es (ha sido) titular, pero ello no justifica su condición de parte. Una posible explicación podría encontrarse en conexión con la cuestión relativa al carácter fraudulento de las contrataciones temporales.

Como se ha señalado ya, el resultado del proceso no afecta al trabajador en absoluto, permaneciendo ajeno a las consecuencias que de él se deriven y que se circunscribirán a la relación empresario-Ente Gestor. Sin embargo, no es menos cierto que, aun de forma instrumental y de cara únicamente a obtener una sentencia de condena del empresario, en el proceso se debatirá e intentará ser probado el carácter fraudulento de la contratación temporal que ha venido uniendo al trabajador con el empresario demandado, hasta el punto de que la condena a éste descansará necesariamente sobre el convencimiento del juzgador acerca de la existencia de un uso abusivo de los contratos temporales. Si se alcanza durante el proceso esta certeza, podría entenderse que el trabajador debiera contar con la posibilidad de ejercer el derecho de acción en su vertiente concreta (artículo $24 \mathrm{CE}$ ) cuando, con base precisamente en la verdadera naturaleza de su relación de trabajo, se condena al empresario al reintegro de prestaciones y cotizaciones. El trabajador, pues, debería poder accionar ante los tribunales por despido, dentro de los 20 días hábiles siguientes a la notificación de la sentencia firme, interpretación ésta que, desde luego, requeriría para su efectividad de las oportunas medidas legislativas ${ }^{36}$. La respuesta, en todo caso, depende de la extensión que quiera darse a la actuación del Ente Gestor, pues, si bien es cierto que desde la misma norma sus efectos se limitan exclusivamente al ámbito recaudatorio, pudiera no ser descabellado aspirar a que lo actuado en ese específico proceso tenga alguna repercusión en materia estrictamente laboral, a través de la impugnación por despido a la que nos hemos referido anteriormente. Desde esta perspectiva, sí parece acertado considerar al trabajador como parte del proceso, a fin de asegurar que la sentencia le será notificada y que podrá posteriormente plantear la oportuna demanda. No obstante, desde la actual configuración

${ }^{36}$ En el mismo sentido, Alemán Cano, J., Los procesos de oficio, op. cit., p. 138, y GoRelli HERnÁNDEZ, op. cit., p. 75. 
normativa, tal interpretación decae totalmente, máxime si se tiene en cuenta que, de haber sido esa la intención, se habrían tomado desde la propia Ley 45/2002 las medidas necesarias para su efectividad. Así las cosas, el trabajador es parte del proceso sin que se sepa muy bien cuál es la utilidad real de esta llamada, que parece colmar más bien exigencias meramente formales.

En otro orden de ideas, desde el análisis que la doctrina hacía de la DA Tercera del RDL 5/2002, se ponían de manifiesto las dificultades probatorias con las que, en atención a una distribución común de la carga de la prueba, tropezaría la Entidad Gestora a la hora de acreditar la fraudulencia de las contrataciones ${ }^{37}$. Con el nuevo proceso del artículo 145 bis LPL se adopta, por el contrario, la misma solución que en los procesos de oficio: las afirmaciones de hechos que se contengan en la comunicación base del proceso harán fe, salvo prueba en contrario, incumbiendo la carga de la prueba al empresario demandado. A este respecto, tal y como se señala en relación a los procesos de oficio, debe tenerse en cuenta que la presunción de certeza se refiere únicamente a las afirmaciones de hechos que se contengan en la comunicación base del proceso, sin que alcance a los razonamientos jurídicos, presunciones o deducciones que consten en la comunicación o en el expediente administrativo ${ }^{38}$. Se trata, por otro lado, de una presunción iuris tantum, de modo que al empresario incumbirá probar la inexactitud de las afirmaciones de hechos referidas o su falta de certeza ${ }^{39}$.

Por otro lado, y según prevé el n. ${ }^{\circ} 4$ del art. 145 bis LPL, la sentencia que estime la demanda de la Entidad Gestora será inmediatamente ejecutiva, con lo que el legislador se aparta en este punto de los procesos de oficio para trasladar a este nuevo proceso una característica propia de los de seguridad social ${ }^{40}$. La sentencia estimatoria, pues, producirá su

${ }^{37}$ Albiol Montesinos, I. y Blasco Pellicer, Desempleo y despido en la reforma laboral del RD-L 5/2002, Tirant lo Blanch, Colección Laboral, n. ${ }^{\circ} 136$, Valencia, 2002, pp. 90 y 91 .

38 Montero Aroca, Iglesias Cabero, Marín Correa y Sampedro del Corral, Comentarios a la Ley de Procedimiento Laboral, Tomo I, Civitas, Madrid, 1993, p. 872. Como apoyo jurisprudencial se ofrecen las SSTCT de 9 de julio de 1981 y 4 de mayo de 1984, entre otras.

39 Desdentado Bonete, A. y De la Puebla Pinilla, A., en AaVV, Coord. I. García-Perrote, La Ley 45/2002 de reforma de la protección..., op. cit., p. 43, entienden que la presunción de veracidad a favor de las afirmaciones de hechos contenidas en la demanda-comunicación de la Entidad Gestora «... supone una ventaja que rompe el equilibrio de las partes en el proceso y que, por tanto, puede afectar al derecho a la tutela judicial efectiva y al principio de igualdad.»

40 Art. 145.4 LPL. 
eficacia normativa aunque contra ella se interponga el recurso procedente $^{41}$ y en caso de posterior revocación de la misma habría de procederse a la restitución al empresario de las cantidades ejecutadas provisionalmente en concepto de prestaciones indebidas.

Por últiıno, el n. ${ }^{\circ} 5$ del artículo 145 bis LPL prevé la comunicación de la sentencia firme a la Inspección de Trabajo y Seguridad Social, pero impide la aplicación de lo dispuesto en el artículo 149.2 LPL. Así, en el caso de que con base en la declaración de hechos probados que figuren en la sentencia se extienda acta de infracción, la autoridad administrativa no podrá iniciar un proceso de oficio cuando el sujeto responsable (el empresario deudor de las prestaciones, en este caso) impugne la misma con base en alegaciones y pruebas de las que se deduzca que el conocimiento del fondo del asunto está atribuido al orden jurisdiccional social según el artículo 9.5 LPOJ.

En cuanto a la delimitación temporal de la actuación del Ente Gestor, la Disposición Transitoria Novena de la Ley 45/2002 señala que ésta sólo podrá tener lugar cuando el último de los reiterados contratos temporales entre trabajador y empresario (aquél, en definitiva, por cuya extinción se solicita la última prestación) «se hubiera concertado tras la entrada en vigor de la presente Ley».

\section{Valoración final}

Nos encontramos ante un nuevo proceso introducido a través del cauce normativo adecuado y dotado, en sus pilares básicos, de una más concreta delimitación que su antecedente inmediato, lo cual, como se dijo, debe ser valorado positivamente. Sin embargo, la mayor lucidez del legislador de la Ley 45/2002 tampoco es merecedora de aplauso. Empezando por la ubicación sistemática del precepto (pocos son, como se han visto, los rasgos que este proceso comparte con los de Seguridad Social regulados en ese mismo capítulo VI) y continuando con los equilibrios procesales que se hacen para llegar a conformarlo. Fundamentalmente basado en los principios que rigen los procesos de oficio, tampoco puede adoptar su nomen, pues ni la demandante es Autoridad Laboral ni, aún superado artificiosamente este escollo, acciona en nombre e interés de otro, lo que hace desaparecer el espíritu propio de

${ }^{41}$ Cabe el recurso de suplicación, a partir de lo dispuesto por el art. 189.1 LPL, respecto de las sentencias recaídas en reclamación de cuantía litigiosa que exceda de 1.803 euros. Cuantía, en todo caso, determinada por la demanda, no por la condena. 
aquellos procesos. Quizás hubiera sido lo más deseable crear para este nuevo proceso un espacio estanco en el articulado de la LPL.

En general, se trata de una norma cargada de nuevas incógnitas que tarde o temprano habrán de ser despejadas; no obstante, y desde una perspectiva sustantiva, resulta positivo el hecho de que a través de este nuevo proceso, si bien de manera mediata, se establezca un mecanismo que, a fin de cuentas, promete repercutir en un mayor control de la contratación temporal fraudulenta, habida cuenta de que el empresario a partir de ahora podrá ser «atacado» desde dos frentes diversos: el tradicional de impugnación por parte del trabajador y el proporcionado por este novedoso proceso ${ }^{42}$.

42 Blanco Martín, J.M., en AAVV, Dtores. P. Gete Castrillo y F. Valdés Dal-Ré, Nuevo régimen jurídico del Despido..., op. cit., p. 118, muestra su inquietud respecto de las reales consecuencias prácticas del 145 bis LPL, ya que « ... teniendo en cuenta que el supuesto de hecho parte inexorablemente de la contratación sucesiva del mismo trabajador y no estrictamente del incumplimiento de las modalidades contractuales, tampoco nos sorprendería que uno de sus efectos consistiese en fomentar la alternancia de trabajadores en el mismo puesto de trabajo, mediante fórmulas de contratación temporal igualmente fraudulentas, pero que no estarían sujetas a la penalización que esta nueva modalidad procesal presupone para el empresario incumplidor». 